\section{of Sport Science}

${ }^{1}$ University of Calgary

https://doi.org/10.5628/rpcd.16.S1.82

Conferência proferida na sessão

"A agenda da ciência - prioridades e desafios."

Integrada no programa de comemorações

dos 40 anos da Faculdade

\section{BACKGROUND}

Sport science has become an intimate partner of high performance sport training, evaluation and competition. Today's high performance athletes are probed, tested and poked physiologically, biomechanically and mentally every step of their way. Often, support teams for athletes at international competitions are greater in number than the number of athletes themselves. There is no doubt that evaluating athletes helps prepare them for important competitions, and aids in the evaluation of training and recovery programs.

Among the sport sciences, the physiology of exercise is arguably the most developed and the one most frequently used and with the longest history. Athletes have known for a long time to pay attention to their heart rates, and the effects of aerobic, anaerobic and interval training, and the effects of resistance training on building muscle mass and strength are well known and documented (e.g. ${ }^{1}$ ). More recently, the use of sport psychology has become standard for international sports delegations, and although the effects of psychological counselling and advising of athletes is hard to measure, in this game of high performance sport, with improvements measured by tiny fractions of a percent, nothing is left to chance anymore.

In considering the future of sport science, I will focus on sport biomechanics, primarily because it is my area of research and also because sport biomechanics has become an underappreciated art. In the 1970s, when national and international societies of biomechanics were first formed, biomechanics research was dominated by sport biomechanists: researchers with a sports background, often coming from physical education and exercise science faculties. Juerg Wartenweiler, the founder of the International Society of Biomechanics and the founder of the first biomechanics lab in Switzerland and one of the first in the world, was a competitive swimmer and a physical education teacher. I propose that the value of biomechanics in sports science and high performance training is underappreciated and systematic biomechanics research in most sports disciplines is sorely lacking The reasons for this state of affairs may be found in underfunding, a lack of visible and clearly identifiable achievements, and an ever increasing scarcity of training possibilities for sport biomechanics researchers.

Sport biomechanics has two primary goals: one of improving performance, the other in the prevention of sports injuries. In the following, I will discuss these two aspects and provide some critical reflections on what we have learnt from sport biomechanics, what might be gained from sport biomechanics and how we might go into the future and revive the once dominating role of sport biomechanics.

\section{WHAT HAVE WE LEARNT}

\section{FROM SPORT BIOMECHANICS?}

Sport biomechanics is the science of analyzing sport movements and the corresponding forces and moments acting on athletes. It is often aimed at improving the efficiency of movement, preventing sports related (overuse) injuries, dealing in the best possible ways with sports implements, and using the muscles in the best mechanical way. Sport biomechanics also deals with the improvement of sports gear, clothing, shoes, etc. Arguably, sport biomechanics has been successful in improving our understanding of the mechanics of movements and associated training of such movements. Improvements in swimming techniques (e.g. ${ }^{2-4}$ ), and aerial movements in tumbling, gymnastics and diving (e.g. ${ }^{5-7}$ ) are just few of the many examples that could be cited here. However, another aspect of sport biomechanics should be the discovery of novel sport techniques that help improve performance and here, one might argue, sport biomechanics has failed, as many of the dramatic improvements in sports techniques have been made by coaches and athletes and not scientists. Maybe there is a lesson to be learnt here, but let's discuss a few examples.

High jump at the 1968 Olympic Games in Mexico City, Dick Fosbury revolutionized the high jump technique by approaching the bar with his take-off leg away from the bar and going head, shoulders and back first over the bar. His technique was in complete contrast to the dominant high jump technique at the time, the straddle, in which the bar was approached with the take-off leg towards the bar, and going over the bar with the chest facing the bar Fosbury perfected the technique by about 1965, but the Fosbury flop was not accepted generally, or even taken seriously until he won the Olympic gold medal in 1968 with a 
jump of $2.24 \mathrm{~m}$. The technique was partly enabled by the new thick foam landing pits, while previously, landing in the high jump was into a sandpit initially, then onto thin rubber mats that would not have allowed for landing on the neck and back as occurs in the Fosbury flop. Nevertheless, it was an athlete, and not a scientist who realized the potential of this way of high jumping. Another technique of high jumping that was proposed almost at the same time as the Fosbury flop was a technique in which a jumper approached the bar front on at almost right angles and performing a forward roll over the bar (Jim Hay, personal communication, 1979). The (likely correct) argument was that crossing the bar in this manner would minimize how much the centre of mass of the jumper had to be raised for clearing the bar successfully. However, the forward roll jump never received serious consideration, likely because the angular momentum required to performing this jump successfully was hard to achieve without sacrificing considerable jumping height. This example illustrates how a technique development by trial and error of an athlete and his coach resulted in a revolution of the high jump technique, while fundamental scientific optimization criteria did not because an important consideration (the forward angular momentum required to perform the forward roll high jump) had been ignored or forgotten.

Cross country skiing. In the 1988 Olympics in Calgary, cross-country skiing was performed for the first time distinguishing between two distinct techniques, the classic technique and the free (or skating) technique. The skating technique is much faster than the classic technique, or, for a given speed of skiing, requires less energy and is less tiring, than the classic technique ${ }^{8}$. Nevertheless, this technique was not invented or inspired by biomechanics research, but was developed over decades by a variety of skiing pioneers. Johan Grøttumsbråten used the skating technique in the World Championships in 1931. However, it had been used previously and Grøttumsbråten's exploit was merely one of the first recorded use of the skating technique in a formal competition. Skating was also used prior to the 1980s in ski orienteering where skiers often found themselves on wide streets and open areas with the snow flattened and no tracks available. Pauli Siitonen used the skating technique in marathon races leaving one ski in the "classic" tracks while angling the other ski outside the tracks and pushing off in a skating-like motion. The American skier Bill Koch had great success in world cup races using the skating techniques in the early 1980 s, and skating received intense scrutiny at the 1982 world championships, and was then officially integrated as a separate discipline into the 1988 Olympic Games. Although it is obvious in hindsight that this technique is much faster and more efficient than the "classic" technique, it was skiers, rather than scientists, who "invented" the technique, refined it, and ultimately popularized it.
Speed skating. Traditional speed skating for most of the $20^{\text {th }}$ century was performed with a blade that was rigidly attached to the skating boot. In the mid-1990s, the clap skate made its international debut and was used uniformly in the 1998 Nagano Olympic Winter Games causing a flood of world records to be broken multiple times. In the clap skate, the blade is not rigidly attached to the boot, but is attached via a hinge joint towards the front of the boot while the rear end of the blade moves away from the boot at push-off ${ }^{9}$. The clap skate was "re-invented" for international speed skating competitions by Dr. Gerrit Jan van Ingen Schenau as part of his doctoral research in the early 1980s. Despite the obvious mechanical advantage that this new skate provided, it took some 15 years for acceptance and another couple of years before it was used universally in international competition. Here, we have an example where sports gear was improved based on scientific considerations However, van Ingen Schenau was a speed skater and the design was not new. Various previous iterations of a skate with a hinge at its front had been considered much earlier and the patent for the clap skate idea was filed in 1894 by Karl Hannes of Raitenhaslach. Interestingly, the original idea for the clap skate was based on the supposition that the hinge joint of the clap skate allowed for greater ankle extension, and thus increased power production, while later research confirmed that the basic advantage offered by the clap skate was that the point of rotation for the skate was moved from the tip of the blade to a point underneath the ball of the foot, thereby facilitating power production ${ }^{10}$. A great idea, pre-emptied almost a century earlier by a hobby skater, allowing for great improvements of speed skating times for reasons other than those assumed initially.

So, what do we gather from these examples of "revolutionary" changes in sports techniques and sports gear described above, and the many other examples (ski jumping, swimming, rowing, pole vaulting, javelin throwing immediately come to mind) not explicitly discussed? What I take from these examples is that sports biomechanics researchers have not been particularly good at identifying revolutionary improvements in sports techniques, while innovative athletes have outdone the researchers. However, biomechanics researchers have been excellent at characterizing, describing and incrementally improving existing techniques and existing sports gear. What appears to be missing is innovative thinking, doing research with coaches and athletes rather than for coaches and athletes, and critically analyzing each sport and how it is performed. I further propose, and this is primarily based on personal observations of researchers in sports biomechanics, that sports research is often a "service" provided to athletes. Physiological testing, biomechanical analysis, strength evaluation competitive analyses are often performed in a descriptive manner with a primary service component aim rather than a scientific approach to sports, athletes and techniques. This is an aspect of sports science research in general rather than just biomechanics research, and it should be changed, at least for scientists working from within academia. 


\section{SPORT BIOMECHANICS}

\section{IS REALLY HARD}

As I am reflecting on this manuscript, I am watching the Rio 2016 Olympic Games. It is fascinating how events are won and lost by the slimmest of margins. In high performance sports biomechanics, we deal with athletes who have perfected, often by trial and error and with little scientific help, their technique and basic physical attributes. A systematic improvement of $1 \%$ for a high performance athlete may mean the difference between winning an Olympic medal and not qualifying for the final. However, it is hard, if not impossible to identify a $1 \%$ increase in performance among the natural human variability, and if a $1 \%$ improvement is achieved, how confident are we that we may attribute it to the biomechanics research we have done with an athlete. The late Jim Hay famously said that if an athlete does not perform well, or does not improve, science might be at fault, but you can never claim credit for one of your athletes when they break world records or win an Olympic gold medal. Sport biomechanics research is hard because improvements in technique are often not easily detected, and if they are, the effects of such improvements on performance are virtually impossible to predict. Optimized techniques by years of training, minute improvements, and human variability make it hard to ever know how much your biomechanics research contributed to an athlete's success.

"Sometimes athletes break world records despite their technique and not because of it" (Jim Hay ca. 1979). The tendency of athletes, coaches and scientists to assume that the best athlete in the world, the world record holder, or the Olympic gold medalist, has impeccable technique is not necessarily correct. Carl Lewis, arguably the most gifted and most recognized male long jumper, with four consecutive Olympic wins, never broke the world record. He had two things against him breaking the world record; the first was the jump of the century by Bob Beamon at the 1968 Olympic Games where Beamon catapulted the world record by $55 \mathrm{~cm}$ from $8.35 \mathrm{~m}$ to $8.90 \mathrm{~m}$ in the span of a few seconds. The second was Carl Lewis' landing distance in the long jump, which was worst among the elite athletes of his time. Lewis had by far the fastest run up speed, and a good (albeit not excellent) conversion of that speed into the long jump. But then his landing technique was estimated to cost him up to $20 \mathrm{~cm}$ (8 inches) compared to his fiercest competitor, Mike Powell, who beat Lewis in one of the most dramatic long jump competitions ever at the World Championships in Tokyo in 1991, and broke the world record while doing so $(8.95 \mathrm{~m})$. Presently, there is nobody who seems to be able to come close to this world record, and just days ago, at the Rio Olympics (2016), the men's long jump was one by a comparatively paltry distance of $8.38 \mathrm{~m}$ which was less by $12-34 \mathrm{~cm}$ compared to the winning distances recorded by Carl Lewis for the Olympic wins between 1984-1996 This explanation does not even include the fact that Carl Lewis merely took one jump (his first attempt) at the 1984 Olympics $(8.54 \mathrm{~m})$ and then watched the competition in order to preserve energy for the $200 \mathrm{~m}$ final which took place later that same afternoon.
Another aspect of sports biomechanics research is the assessment and prevention of sports injuries. There have been dozens of studies on cutting maneuvers in a variety of sports (e.g. ${ }^{11}$ ) and the correct landing techniques in gymnastics or following a jump shot in basketball or handball (e.g. ${ }^{12}$ ). However, arguably the most studied sports injuries are overuse injuries associated with running (e.g. ${ }^{13-15}$ ), but despite four decades of intense research into running injuries, the incidence of injury occurrence has remained the same (e.g. ${ }^{16,17}$ ). One hypothesis after the other about the cause of running injuries has entered the field, has been published and discussed, then rejected, and after a certain time seems to be resurrected. After forty years of research, the state of the art of the scientific insight gained into the causes of running injuries and how to prevent them has been summarized by a leading scientist in the field as follows ${ }^{18}$ : ".... a runner intuitively selects a comfortable product using their own comfort filter that allows them to remain in the preferred movement path. This may automatically reduce the injury risk and may explain why there does not seem to be a secular trend in running injury rates." In other words, buy the most comfortable running shoe and that will minimize your risk for injury.

In a recent review of running injury research, one basic conclusion was that scientists in the running injury field have treated runners like laboratory rats rather than collaborators with potential insight about how their running injuries might have come about. It was proposed to do running research with an active involvement of the runners rather than merely giving them instructions on how to run over the force platform in a biomechanics laboratory ${ }^{19}$. I agree ${ }^{20}$ but would further add that biomechanics is the scientific field that combines biology with mechanics. In running injury research, it seems biomechanists were focused on the mechanics of injuries primarily, while virtually completely ignoring the biology. What if at the end of the day, slight differences in foot pronation, small differences in hip abductor strength, or minute changes in the impact peak ground reaction forces are meaningless risk factors for running injuries, but the mechanical properties of a runner's bones, ligaments, cartilages or muscles might be the primary and dominant factor that determines if a runner is at risk for injury? Or do we really believe that some world leading athletes can run in excess of $200 \mathrm{~km}$ per week for many years without substantial injury while others can barely accumulate $20 \mathrm{~km}$ per week without incurring multiple and serious injuries per year because of running technique and mechanical loading. Could it not be, that it is not the loading but the properties of the musculoskeletal tissues that are being loaded that make the difference? Sometimes, when an area of research is dominated by strong individuals, intuition and creative thinking might get lost, and the field might suffer for that. This reality may be a danger in sport biomechanics, where there are often just a few individuals in a given area, which might diminish discourse, controversy, and thus creative and novel thinking and approaches. It will be essential for sport biomechanics to have strength in numbers, in order for an open discourse, challenging theories, and novel ideas to emerge and make the field stronger than it is at present. 


\section{SUCCESSFUL SPORT SCIENCE}

\section{RESEARCH FOR THE FUTURE}

In the following, I would like to make some recommendations that I think are required for sports science in general, and sports biomechanics in particular, to be successful in the future. These recommendations are by no means complete, nor are they arrived at by some intense review of the field by a group of scientists. Rather, they are my personal reflections on the field of sports biomechanics, the changes that have occurred over the years, and the present requirements for sports sciences research. Some of the recommendations follow directly from what has been discussed above, while some are unrelated but nevertheless may be important. Also, the recommendations are not given in some sort of priority listing. Rather, depending on the personal situation of each researcher, the priorities will differ and some recommendations may not apply.

UNDERSTANDING THE SPORT YOU ARE RESEARCHING

In some of the examples mentioned above, I indicated that many of the revolutionary changes in sports techniques were initiated and perfected by athletes and coaches. I discussed the Fosbury flop high jump technique, the skating technique in cross-country skiing and the clap skate in speed skating. However, I could have easily discussed many othe "revolutionary" inventions in technique or sports implements which were associated with vast improvements in performance: the V-technique in ski jumping, underwater swimming, the movable rig in rowing, the different evolutions of the material and the bending of the pole in pole vaulting, and the "old" javelin that was so good that it had to be disallowed because of athletes throwing it in excess of $100 \mathrm{~m}$, thus endangering the safety of officials and track athletes competing in the same stadium. All these technical changes can be traced back to athletes, coaches and inventors familiar with the sport, and not to sport scientists. Therefore, it appears that scientists that are intimately familiar with a sport, because they competed and/or coached in that sport, or they have some other deep knowledge of the sport, have a distinct advantage over a "general" sport biomechanist, who researches running injuries (but has never been a runner) or optimal swimming technique (but has never been a swimmer).

Recommendation. Know the sport you are studying intimately, and if you are not, make sure you have somebody on the team who does. Otherwise, chances of making meaningful scientific and practical contributions seem dramatically reduced.

INVOLVE COACHES AND ATHLETES AS ACTIVE PARTICIPANTS

When studying at the University of Iowa, my PhD supervisor, Jim Hay, was charged and received financial support from the United States Track and Field Association to prepare the long - and triple jumpers for the Olympic Games 1984 in Los Angeles. One of the mantras of this multiple year research project was to involve the Olympic hopefuls who we were testing filming and analyzing into the project. In order to achieve this goal, we invited coaches and athletes twice a year to the University of Iowa where we discussed our research with them, and where we tried to find out how our research might affect them, what questions they had, and maybe most importantly, what they thought of how we could help them the most. At the end of the day, the men's long jumpers and triple jumpers won three of the potential six medals (gold in long jump and triple jump, and silver in the triple jump). However, there is no way of saying how much our research contributed to that success, if at all. But having the athletes and coaches directly involved, and using their input to shape our research helped formulate questions and approaches that otherwise might not have been considered.

Similarly, in a recent paper published in the Journal of Sport and Health Science, Hulme and Finch ${ }^{19}$ argued that the reason why running injury research has not resulted in a reduction of running injuries is, at least in part, associated with the fact that most research in this area is conducted without an involvement of the runners. Often, running injury research is epidemiological in nature, and the runners are unknown to the scientists, or in biomechanics studies, runners come to the lab and are tested, measured, filmed and analyzed in a variety of ways, but rarely, if ever, are they asked about why they think they got injured, or what they think is the critical factor for them having become injured. Being a competitive runner for over 50 years, I have developed a good sense of what I can do and what I cannot before I get injured, and when I get injured, I usually have a good idea why the injury happened and what I did (or did not do) to become injured. Of course, such subjective statements from athletes must be treated with caution, but not using this information at all has led to a situation in a field of sports biomechanics research that has stalled ever since its inception decades ago.

Recommendation. Involve coaches and athletes actively in your sport science research. Take advantage of their knowledge of the sport, and their experience about what helps them improve performance and keeps them injury free.

INSTANTANEOUS (FAST) TURNAROUND TIME OF RESULTS AND RECOMMENDATIONS:

One of the best things a coach can deliver is instantaneous feedback on a performance and instantaneous recommendations on how to improve performance. This is particularly true in events where an athlete might have repeat performances on a given competition day. The field events in track are a perfect example. A long jumper has six attempts to produce the best jump possible. A coach can provide trivial feedback (how far the athlete was from the front of the take-off board) to sophisticated feedback on the flight or landing phase of a jump. Similarly, in many other sports, instantaneous feedback may help an athlete adjust during the competition: gymnastics and diving come to mind, where an athlete typically performs multiple times during a competition. However, it is one thing to provide subjective 
(coaching) type feedback to an athlete and direct scientific information. Nevertheless, fast feedback is a requirement for effective sport science to make an impact on the athlete. Providing a report six months following a long jump competition is not as effective as providing a report within a week. Today's technology allows for virtually instantaneous feedback to athletes using scientific data. For example, bobsled tracks can be modelled theoretically, and the optimal path of a bobsled (path that minimizes the time for the bobsled run) along that track can be calculated. During training and competitive runs, the location of the bobsled along the track, and its deviation from the optimal path, can be monitored, analyzed and visualized virtually instantaneously, and the bobsled pilots can be given feedback immediately following their run, for possible improvements in the remaining runs.

Similarly, many years ago, Mont Hubbard (personal communication) measured the release speed, release angle and angle of attack of javelins during javelin throwing. By modeling the airborne behavior of javelins and the wind conditions, the optimal release angle and angle of attack (resulting in the maximal distance of the throw) could be calculated "instantaneously" and provided to the athlete for the next round of throws with feedback about what the actual angles of release and of attack were. With today's technology, I can envision many examples of how we can provide athletes in a variety of fields with instantaneous (fast) feedback, thereby providing a service similar to that of the coach, without the errors that subjective judgment by a coach might introduce into the equation.

Recommendation. As sport scientists, we need to find ways to give scientific feedback to athletes about their technique in an "instantaneous" manner. For sports with a certain duration (rowing, time trials in cycling, swimming), ways of providing feedback on performance and technique during training and competition should be explored.

FUNDING:

No research happens without funding, and in most countries, sport biomechanics research does not get funded (easily) by federal granting agencies or agencies typically available to academic researchers. Colleagues at my university have been successful in establishing long-term collaborations, relationships, and financial support with sports businesses. These relationships have been successful and financially rewarding, but there are limitations of such collaborations that may include non-disclosure, or delayed disclosure agreements, research driven by financial rather than scientific interests, and accountability to a non-scientific, non-peer-review system with its own rules. For some university researchers, this flies in the face of academic freedom and public accountability of investigator and curiosity driven research, while for others, this is no hindrance. For some researchers, working with business partners is much simpler than working in the confines of the scientific peer-review system, where one needs to continuously convince experts in the field of the quality of one's research.
However, I feel there is a largely neglected source of funding for sports science research in general and sport biomechanics research in particular, and that is the regular federal granting agencies set up by most countries who invest heavily into research and technology development. Sport has such an impact in today's society, it creates enormous revenues, and, like it or not, is often used as a proxy for how well countries are doing on the global scale (especially around the time of the Olympic Games), that it should be relatively easy to convince government officials and the sports associated industries, to provide a small amount of their income from sports to scientific research in sports. It seems to me that senior sport science researchers in each country could make a convincing case that a small (percentage) investment of sports-related revenues would make a large (absolute) impact on funding for sport science, and ultimately to the performance of a country's athletes in international competitions. I do not think this argument has been made sufficiently and strongly enough in many countries, and I believe it could be made successfully in most countries invested in international sports.

Recommendation. Senior sport scientists need to develop country-wide strategies on how to approach governments successfully to invest in sport science research. These strategies will invariable vary from country to country as the specific conditions of each country need to be carefully assessed. I believe that it is possible in this manner to increase sport science research funding by a factor of 5-10 in most countries invested in international sports competition. But it will require sport scientists to form strategic alliances and approach this funding project in a serious and well-organized and well-strategized manner.

\section{FINAL COMMENTS}

There are many other recommendations that could have been made here to keep sport sciences research and sports biomechanics alive and well. One of the recommendations that I decided to leave out for brevity is the way we need to conceive Future Laboratories in sport science. We need to bring the laboratory testing to the athletes and to the training and competition sites. I see a future in sport science where Olympic and other international competition facilities are developed in combination with scientists. Force platforms directly embedded in all jumping and throwing events of track and field, weight lifting training facilities with measurement systems monitoring each repetition and each set and the work performed with each muscle group, and aquatic arenas with force measurement systems for starts and turns and standard 3-dimensional underwater movement analysis systems, etc. There is no end to what can be done, and monitoring and assessing athletes training and competing could (should) be done continuously rather than just on that one occasion every year when the national team comes for testing to the university laboratory. 
Another discussion point initially on my list was academic training facilities for sport science and sport biomechanics researchers. With the demise of sport biomechanics, its poor funding, and many of the traditional sport biomechanics researchers doing other things than "just" sport biomechanics, the number of places where sport biomechanics students can be trained has vastly diminished from 35 years ago. A strategic funding plan, improved recognition of sport biomechanics, and well equipped laboratories would go a long way for helping the next generation of sports scientists and sport biomechanics researchers.

Sport biomechanics is an exciting field with much potential for excellent scientific research and improvement of athletic performance and reduction of sports related injuries. It is a challenging field as improvements in high performance athletes are hard to measure, and the impact of the science cannot be quantified easily. However, there are vast unexplored areas in sport biomechanics research that may hopefully be a source of excitement for some of the young biomechanics researchers looking for a career in sports science. My favourite research topic is the integration of muscle mechanics into the realm of high performance sport. A world class shot putter should release a shot at about $42-43^{\circ}$ from the horizontal for optimal trajectory of the shot. However, world class shot putters release the sho at considerably lower release angles (in the $35-38^{\circ}$ range; ${ }^{21}$ ). Similarly, cyclists exert forces on the crank that are in line with the crank, while only forces tangential to the crank produce mechanical work. Why would a cyclist "waste" force in a direction that does not contribute to the propulsion of the bike ${ }^{22}$. There are simple answers to these questions based on the musculoskeletal anatomy of the human body and the mechanics of muscles. There are dozens of examples where basic mechanics gives one result for optimal performance, but this result may not apply within the confines and constraints of the human musculoskeletal system and the work and force production properties of our skeletal muscles. I sincerely hope that one day a series of young and talented researchers come along to approach sports performance based on a background of a solid understanding of muscle mechanics. An exciting field, with currently no competition. What an outlook for a fulfilling career!
1. Åstrand PO, Rodahl K, Dahl HA, Stromme SB. Textbook of Work Physiology: Physiological Bases of Exercise. 4th ed. Human Kinetics, USA; 2003

2. Guimaraes ACS, Hay JG. A mechanical analysis of the grab starting technique in swimming. Int $\mathrm{J}$ Sport Biomech 1985 Feb; 1 (1):25-35.

3. Hay JG, Thayer AM. Flow visualization of competitive swimming techniques - the tufts method. J Biomech 1989;22(1):11-\&.

en T, Kluft M. Effect of propelling surface size on the mechanics and ent frontcrawl 5. Yeadon MR. The simulation of aerial movement--I A mathematical inertia model of the human body. Biomech 1990;23(1):67-74.

6. Yeadon MR. The simulation of aerial movement-III. The determination of the angular momentum of the human body. J Biomech 1990;23(1):75-83

7. Yeadon MR, Atha J, Hales FD. The simulation of aerial movement--IV. A computer simulation model. Biomech 1990;23(1):85-9.

8. Bilodeau B, Roy B, Boulay MR. A Comparison of 3 Skating Techniques and the Diagonal Stride on Heart-Rate Responses and Speed in Cross-Country Skiing. Int J Sports Med 1991 Feb;12(1):71-6.

. van Ingen Schenau GJ, De Koning J J de Groot G. A simulation of speed skating performances based on a power equation. Med Sci Sports Exerc 1990;22:718-28. 10. van Ingen Schenau GJ, de GG, Scheurs AW, Meester $\mathrm{H}$, De Koning JJ. A new skate allowing powerful plantar flexions improves performance. Med Sci Sports Exerc 1996 Apr;28(4):531-5.

11. Besier TF, Lloyd DG, Cochrane JL, Ackland TR. External loading of the knee joint during running and cutting maneuvers. Med Sci Sports Exerc 2001:33:1168-75.

12. Dufek JS, Bates BT. Biomechanical factors associated with injury during landing in jump sports. Sports Med 1991;12:326-37

3. Taunton JE, Ryan MB, Clement DB, McKenzie DC Lloyd-Smith DR, Zumbo BD. A retrospective case-control analysis of 2002 running injuries. Br J Sports Med 2002;36:95-101.

14. Herzog W. Running Injuries: Is It a Question of Evolution, Form, Tissue Properties, Mileage, or Shoes? Exerc Sport Sci Rev 2012 Apr;40(2):59-60.

15. Samaan CD, Rainbow MJ, Davis IS. Reduction in ground reaction force variables with instructed barefoot running. Journal of Sport and Health Science 2014 Jun;3(2):143-51.
16. Van Mechelen W, Hlobil H, Kemper HC. Incidence severity, aetiology and prevention of sports injuries. Sports Med 1992;14:82-99.

17. van Gent BR, Siem DD, van Middelkoop M, van Os TA, Bierma-Zeinstra SS, Koes BB. Incidence and determinants of lower extremity running injuries in long distance runners: a systematic review. $\mathrm{Br} J$ Sports Med 2007.

18. Nigg BM, Baltich J, Hoerzer S, Enders H. Running shoes and running injuries: mythbusting and a proposal for two new paradigms: 'preferred movement peth' and 'comfort filter'. Br J Sports Med 2015.bjsports-2015

19. Hulme A, Finch CF. The epistemic basis of distance running injury research: A historical perspective. Journal of Sport and Health Science 2016;5:172-5.

20. Herzog W. The problem with running injuries Journal of Sport and Health Science 2016 Mar 8:5:171-doi:10.1016/j.jshs.2016.03.001.

21. Linthorne NP. Optimum release angle in the shot put. J Sports Sci 2001;19:359-72.

22. Kautz SA, Neptune RR. Biomechanical determinants of pedaling energetics: internal and external work are not independent. Exerc Sport Sci Rev 2002;30(4):159-65. 